\title{
A Case Report on Scalp edema in a case of HSP in a young adult
}

\section{Thapaliya $S^{1}$, Nepal $\mathbf{M}^{2}$, Nepal B³ and Pathak R'}

${ }^{1}$ Tribhuvan University Teaching Hospital, Maharajgunj, Kathmandu

${ }^{2}$ Om Hospital and Research Center, Chabhil, Kathmandu

${ }^{3}$ Nepal Medical College, Attarkhel, Jorpati, Kathmandu

Keywords: Henoch Schonlein Purpura, Scalp edema, Adult HSP

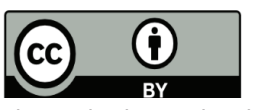

This work is licensed under a Creative Commons Attribution 4.0 Unported License.

\section{Abstract}

Henoch Schonlein Purpura (HSP) is a systemic small vessel vasculitis which most commonly affects children. HSP is characterized by non-thrombocytopenic palpable purpura, arthritis or arthalgia, gastrointestinal and renal involvement. Scalp edema is uncommon in children over 3 years. Early recognition, especially outside of the typical age group, with appropriate management can reduce morbidity and organ damage. We present a case of a young adult with HSP who

\section{Case Report:}

An eighteen year old boy presented to TUTH (Tribhuvan University Teaching Hospital) ER (Emergency Room) with 4 days epigastric pain that increased with food intake, and passage of black tarry stool for 2 days. A day prior to his presentation, he developed skin rashes over the extensor surfaces of his legs and his buttocks. He also complained of progressive fatigue, joint pain over the lower limbs, loss of appetite, fever and shortness of breath on exertion.

He was subsequently admitted to the General Ward of Department of Internal Medicine. Physical examination revealed pallor, tachycardia with a regular heart rate of 110 beats per minute and a respiratory rate of 20 breaths per minute. His blood pressure was $100 / 60 \mathrm{mmHg}$ and his axillary temperature was $100.7^{\circ} \mathrm{F}$. His abdominal examination revealed diffuse tenderness without rebound tenderness. Digital Rectal examination revealed tarry stool on the examining finger. Skin examination revealed petechial rashes over his eyelids (as in the picture below) and over his trunk and extensor surface of his lower limbs. His respiratory, cardiovascular and neurological examinations did not reveal any abnormal findings. There was no swelling, redness or tenderness of any joint.

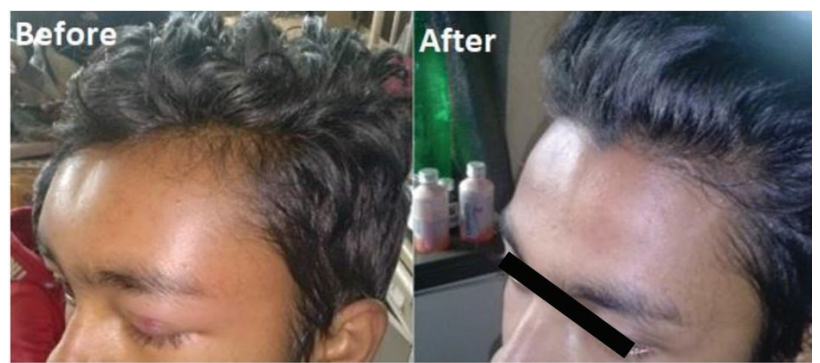

Fig 1: Scalp edema before and after treatment

Correspondence Author

Sabin Thapaliya, Tribhuvan University Teaching

Hospital, Kathmandu, Nepal.

Email: sabinthapaliya@gmail.com 
His laboratory investigations showed Hemoglobin - $9.2 \mathrm{gm} / \mathrm{dL}$, Total Leukocyte Count: 11000/uL (Neutrophils 60/Lymphocytes 36), Platelet counts: $2,20,000 / \mu \mathrm{L}$, ESR- $55 \mathrm{~mm}$ in First hour, Peripheral blood smear showed Normochromic, Normocytic anemia with Adequate Platelets. Blood biochemistry reports showed Na- $134 \mathrm{mEq} / \mathrm{L}, \mathrm{K}-3.8 \mathrm{mEq} / \mathrm{L}$, Urea: $8.2 \mathrm{mmol} / \mathrm{L}$, Creatinine: $0.8 \mathrm{mg} / \mathrm{dl}$ and Random Blood Sugar: $6 \mathrm{mmol} / \mathrm{L}$. Urine Routine and microscopy showed RBCs 10-12/HPF, WBCs: 3-4/HPF, Protein: 2+ (with subsequent $24 \mathrm{hr}$ Urinary Total Protein quantification - 1.2 gm/day) and No casts or Crystals. His serological tests for HIV, $\mathrm{HBsAg}$ and HCV by Elisa were Negative. X-ray of the Abdomen in Erect and Supine positions were Normal. USG abdomen revealed Edematous loops of small bowel with interloop collection.

He was managed symptomatically with fluids and NSAIDs, and PCV was sent 6 hourly. On the 1st day of admission, the patient had progressive abdominal pain and continuing melena. Blood (Packed Red blood cells) transfusion was done when the hemoglobin level dropped to $8 \mathrm{gm} \%$ with the target of $\geq 10 \mathrm{gm} \%$.

On the 2 nd day of admission, the patient developed forehead and scalp swelling with significant pain. The swelling was boggy and fluctuant and had significant tenderness (picture shown below). Ultrasonogram revealed subcutaneous fluid collection in the forehead and scalp. His Upper Gastrointestinal Endoscopy was normal. Investigations repeated turned out to be similar. Injection Methyl Prednisolone was started and then continued for 3 days at $500 \mathrm{mg} /$ day. On the 3rd day, skin biopsy was done and sent for histo-pathological and immunofluorescence studies. Blood culture report was negative for any growth. On the 4th day, the scalp swelling decreased and the petechial rashes diminished in both number and size.

The patient was discharged on the 6th day with oral Prednisolone $40 \mathrm{mg}$, and was followed up in the Internal Medicine OPD (Out Patient Department) after 2 weeks with Histopathology reports which revealed leukocytoclastic angiitis with neutrophilic predominance and the Immuno-histochemistry report which revealed IgA deposits in the dermis. He was then diagnosed as a case of HSP. He had no complaints during follow-up visit and and his laboratory reports showed $\mathrm{Hb}$ of $10 \mathrm{gm} \%$, normal Urine routine examination and normal ESR.

\section{Discussion:}

Henoch Schonlein Purpura (HSP) is a systemic small vessel vasculitis characterized by non-thrombocytopenic palpable purpura, arthritis or arthalgia, gastrointestinal and renal involvement, and rarely, other systems (lungs, central nervous system, genitourinary tract). ${ }^{1,2,3}$ HSP is the most common cutaneous vasculitis in children comprising up to $90 \%$ of cases. ${ }^{4,5}$ Peak age of incidence is 4-6 years and $90 \%$ of HSP cases occur before the age of 10 years. The true incidence of this disease may be underreported because of its self-limited nature. ${ }^{1,6}$

Facial edema as a manifestation of HSP is mainly observed in children less than 2 years of age. ${ }^{7,8}$ Subcutaneous edema, especially localized at the feet and ankles, is also a common finding in HSP. Although not a common presentation, scalp edema can occur in HSP. ${ }^{9}$ However it is uncommon in children over 3 years.
Given the fatigue and fever with multisystemic involvement in our patient, systemic vasculitis remains one of the top differential diagnoses. The presence of skin rashes with joint pain suggest small vessel vasculitis. Henoch-Schonlein Purpura, Microscopic Polyangiits, Infective Endocarditis and Hypersensitivity Vasculitis are among the important differential diagnoses. ${ }^{10,11}$

The presentation of the patient as gastro-intestinal bleed, subcutaneous edema and proteinuria suggests HSP as the provisional diagnosis. Final diagnosis of HSP is based on the relevant history and physical examination supported by the characteristic skin biopsy and Immunohistochemistry. The treatment of HSP has been based on the severity of the disease. The prophylactic role of steroid in the treatment of HSP is a controversial topic in the treatment of adults, although recent evidence supports against its use in uncomplicated disease in the children. ${ }^{12}$ In the given clinical scenario with active vasculitis and Gl-bleed with inability to take the medicine orally, the optimum treatment would be intravenous potent steroid, preferably methyl Prednisolone. ${ }^{11}$ The proteinuria accompanying the other features likely represents the ongoing glomerulonephritis. The treatment of the renal manifestations of HSP is also based on the severity of involvement of the renal function; measured by the amount of the proteinuria and the level of the serum creatinine levels. ${ }^{13}$

Although classically HSP presents with pain abdomen, rash and joint pain, many a times it also presents with swelling of loose tissues in the body like eyelids, scrotum and scalp and sometimes it also may present as necrotic skin lesions. It may present as vasculitis of the gastrointestinal system and present as a Gl bleed. ${ }^{15}$ Clinical suspicion and early diagnosis helps in the vital and urgent management as the definitive diagnostic investigations take time to be of clinical use.

\section{Conclusion}

The clinical suspicion of a systemic vasculitis should be made on clinical grounds and depending on the disease status, empirical treatment should be started while the confirmatory test results are awaited. Early recognition, especially outside of the typical age group, with appropriate management can prevent complications and can be life saving.

\section{Acknowledgements}

ICCU and Annex II staff at Tribhuvan University Teaching Hospital, Maharajgunj.

\section{Conflict of Interest: None.}

Consent: Case Report Consent form was signed by the patient and consent for the publication of the photograph was also taken. 
References:

1 Roberts P, Waller T, Brinker T, Riffe I, Sayre J, Bratton R. Henoch-Schönlein Purpura: A Review Article. South Med J. 2007;100(8):821-824. [DOI]

2 Gedalia A. Henoch-Schönlein purpura. Curr Rheumatol Rep. 2004;6(3):195-202. [DOI]

3 Zhang $Y$, Huang $X$. Gastrointestinal involvement in HenochSchönlein purpura. Scand J Gastroenterol. 2008;43(9):10381043. [DOI]

4 E. C. Ebert, "Gastrointestinal manifestations of HenochSchönlein purpura," Digestive Diseases and Sciences, vol. 53, no. 8, pp. 2011-2019, 2008. [DOI] [PubMed]

5 Tizard E, Hamilton-Ayres M. Henoch Schonlein purpura. Archives of Disease in Childhood - Education and Practice. 2008;93(1):1-8. [DOI]

6 Watts R, Scott D. Epidemiology of the Vasculitides. Semin Respir Crit Care Med. 2004;25(05):455-464. [DOl]

7 Trapani S, Micheli A, Grisolia F et al. Henoch Schonlein Purpura in Childhood: Epidemiological and Clinical Analysis of 150 Cases Over a 5-year Period and Review of Literature. Semin Arthritis Rheum. 2005;35(3):143-153. [DOl]

8 Nussinovitch M, Prais D, Finkelstein Y, Varsano I. Cutaneous manifestations of Henoch-Schonlein purpura in young children. Pediatr Dermatol. 1998;15(6):426-428. [DOI]
9 Hopkins A, Salahuddin A. A Perplexing Case of Henoch Schonlein Purpura. Abstract published at Hospital Medicine 2015, March 29-April 1, National Harbor, Md. Abstract 757. Journal of Hospital Medicine. 2015; 10 (suppl 2).

10 Ghetie D, Rudinskaya A, Raut R. The Enigma of Vasculitis. Int J Rheumatol. 2010;2010:1-3. [DOI]

11 Sohagia A, Gunturu S, Tong T, Hertan H. Henoch-Schonlein Purpura-A Case Report and Review of the Literature. Gastroenterol Res Pract. 2010;2010:1-7. [DOI]

12 Gurusamy PSR, Janagaraj PD. The Role of Prophylactic Corticosteroids in Henoch Schonlein Purpura. Journal of Asian Medical Students' Association. 2013;1(1):1-3.

13 Pillebout E. Henoch-Schonlein Purpura in Adults: Outcome and Prognostic Factors. Journal of the American Society of Nephrology. 2002;13(5):1271-1278. [DOI]

14 Dhanjal S, Saso A, Eleftheriou D, Laurent S. Necrotic cutaneous vasculitic skin lesions: a case of atypical Henoch-Schönlein purpura in a child with heterozygosity for factor V Leiden. BMJ Case Rep. 2017:bcr2016218903. [DOI]

15 Sharma A, Wanchu A, Kalra N, Singh S, Bambery P. Successful treatment of severe gastrointestinal involvement in adultonset Henoch-Schönlein purpura. Singapore Med J. 2007 Nov;48(11):1047-50. 